University of Nebraska - Lincoln

DigitalCommons@University of Nebraska - Lincoln

USGS Staff - Published Research

US Geological Survey

$10-22-2015$

\title{
The vulnerability of Indo-Pacific mangrove forests to sea-level rise
}

Catherine E. Lovelock

The University of Queensland

Donald R. Cahoon

United States Geological Survey, dcahoon@usgs.gov

Daniel A. Friess

National University of Singapore

Glenn R. Guntenspergen

United States Geological Survey, Glenn_Guntenspergen@usgs.gov

Ken W. Krauss

United States Geological Survey

See next page for additional authors

Follow this and additional works at: https://digitalcommons.unl.edu/usgsstaffpub

Part of the Geology Commons, Oceanography and Atmospheric Sciences and Meteorology Commons, Other Earth Sciences Commons, and the Other Environmental Sciences Commons

Lovelock, Catherine E.; Cahoon, Donald R.; Friess, Daniel A.; Guntenspergen, Glenn R.; Krauss, Ken W.; Reef, Ruth; Rogers, Kerrylee; Saunders, Megan L.; Sidik, Frida; Swales, Andrew; Saintilan, Neil; Thuyen, Le Xuan; and Triet, Tran, "The vulnerability of Indo-Pacific mangrove forests to sea-level rise" (2015). USGS Staff-- Published Research. 988.

https://digitalcommons.unl.edu/usgsstaffpub/988

This Article is brought to you for free and open access by the US Geological Survey at DigitalCommons@University of Nebraska - Lincoln. It has been accepted for inclusion in USGS Staff -- Published Research by an authorized administrator of DigitalCommons@University of Nebraska - Lincoln. 


\section{Authors}

Catherine E. Lovelock, Donald R. Cahoon, Daniel A. Friess, Glenn R. Guntenspergen, Ken W. Krauss, Ruth

Reef, Kerrylee Rogers, Megan L. Saunders, Frida Sidik, Andrew Swales, Neil Saintilan, Le Xuan Thuyen, and Tran Triet 


\title{
The vulnerability of Indo-Pacific mangrove forests to sea-level rise
}

\author{
Catherine E. Lovelock ${ }^{1,2}$, Donald R. Cahoon ${ }^{3}$, Daniel A. Friess ${ }^{4}$, Glenn R. Guntenspergen ${ }^{3}$, Ken W. Krauss ${ }^{5}$, Ruth Reef ${ }^{1,2,6}$, \\ Kerrylee Rogers ${ }^{7}$, Megan L. Saunders ${ }^{2}$, Frida Sidik ${ }^{8}$, Andrew Swales ${ }^{1,9}$, Neil Saintilan ${ }^{10}$, Le Xuan Thuyen ${ }^{11} \&$ Tran Triet $^{11,12}$
}

Sea-level rise can threaten the long-term sustainability of coastal communities and valuable ecosystems such as coral reefs, salt marshes and mangroves ${ }^{1,2}$. Mangrove forests have the capacity to keep pace with sea-level rise and to avoid inundation through vertical accretion of sediments, which allows them to maintain wetland soil elevations suitable for plant growth ${ }^{3}$. The IndoPacific region holds most of the world's mangrove forests 4 , but sediment delivery in this region is declining, owing to anthropogenic activities such as damming of rivers ${ }^{5}$. This decline is of particular concern because the Indo-Pacific region is expected to have variable, but high, rates of future sea-level rise ${ }^{6,7}$. Here we analyse recent trends in mangrove surface elevation changes across the Indo-Pacific region using data from a network of surface elevation table instruments ${ }^{8-10}$. We find that sediment availability can enable mangrove forests to maintain rates of soil-surface elevation gain that match or exceed that of sea-level rise, but for 69 per cent of our study sites the current rate of sea-level rise exceeded the soil surface elevation gain. We also present a model based on our field data, which suggests that mangrove forests at sites with low tidal range and low sediment supply could be submerged as early as 2070 .

Intertidal mangrove forests occur on tropical and subtropical shorelines, and provide a wide range of ecosystem services, including the support of fisheries, coastal protection and carbon sequestration, which are collectively and conservatively estimated to be worth US $\$ 194,000$ per hectare per year (refs 11, 12). Although mangrove tree species are able to tolerate inundation by tides, they can die and their former habitat can convert to open water or tidal flats when sealevel rise (SLR) causes the frequency and duration of inundation to exceed species-specific physiological thresholds ${ }^{13}$, resulting in shoreline retreat ${ }^{14}$. In low-sediment-supply systems such as Caribbean atolls, the capacity of the soil surface to keep pace with SLR is strongly dependent on the accumulation of organic matter derived from roots that decompose slowly in anaerobic soils ${ }^{15}$. But sediment accretion on the soil surface in the Indo-Pacific region can also play a crucial role in surface elevation gains ${ }^{16}$.

Changes in the elevation of the soil surface over time can be measured using the surface elevation table-marker horizon (SET-MH) methodology ${ }^{8,9}$, which has been widely used and recommended for monitoring intertidal surface-elevation trajectories in coastal wetlands ${ }^{10}$. Here we use an extensive network of SET-MH stations (Fig. 1) with records of 1-16.6 years in length to investigate the role of sediments in maintaining surface elevation gain in these IndoPacific mangrove forests and to identify their vulnerability to future SLR. Recent trends in mangrove surface elevation change across 27 sites in the Indo-Pacific (Supplementary Table 1) were analysed with respect to environmental factors, including suspended-matter concentration and the regional rate of SLR obtained from tide gauges. Future vulnerability to SLR was modelled on the basis of the results of this analysis using a surface elevation change model and likely future SLR scenarios.

Throughout the Indo-Pacific region, we found that mangrove soilsurface elevation gains are strongly dependent on rates of accretion of sediment on the soil surface (Fig. 2a) as well as subsurface organic matter accumulation, which has been observed in sites in the Caribbean ${ }^{15}$. One site in southeast Java, Indonesia, has particularly high rates of surface accretion, owing to a mud-volcano eruption ${ }^{17}$, but even with this site removed from the analysis, surface elevation gain remains significantly correlated with sediment accretion $\left(R^{2}=0.259, P<0.001, F\right.$ test $)$. As expected from theoretical models ${ }^{18}$, we found that the concentration of total suspended matter (TSM) in the water column, derived from remotely sensed MERIS (medium resolution imaging spectrometer) imagery, was proportional to surface accretion (Fig. 2b) and to surface elevation gains (Fig. 2c), although the relationship between surface elevation and TSM was more variable than that observed between surface elevation and locally measured rates of surface accretion. These relationships link the supply of sediments to the maintenance of soil elevation relative to sea level in mangrove forests at regional scales within the Indo-Pacific region. Other factors (such as rate of SLR, geomorphology, habitat and dominant species) explained a smaller proportion of the variation in the surface elevation gains (Extended Data Table 1). On the basis of our network of SET-MH sites, we conclude that sediment supply is important to surface elevation gains and therefore to preventing mangrove-forest loss in the future.

We found that $69 \%$ of surface elevation records in the Indo-Pacific data set (90 out of a total of 153 SET-MH stations) had rates of surface elevation gain that were less than the long-term rate of SLR for the region (Extended Data Fig. 1b). The remaining 31\% of the records are from sites in Australia, New Zealand, Vietnam and Indonesia. Many of the sites that had rates of surface elevation gain less than SLR also exhibited shallow subsidence (Extended Data Fig. 1a). Shallow subsidence can be caused by a range of factors that increase compaction of the near-surface sediments and that are responsive to local environmental factors, including forest degradation ${ }^{19}$. But whether subsidence and the 'elevation deficit' relative to local rates of SLR indicate vulnerability of these mangrove forests to loss with increasing rates of SLR is unknown. If the topography allows the mangrove forest to migrate landward, with no anthropogenic barriers (such as infrastructure or flood-defence barriers), then mangroves may delay submergence by 'back-stepping' into adjacent habitats ${ }^{20}$. However, barriers to landward expansion of mangrove forests occur throughout the Indo-Pacific region, particularly in sites that have intensive aquaculture, urban development and low-lying agricultural land. We have therefore assumed that broad-scale landward retreat of human settlements in

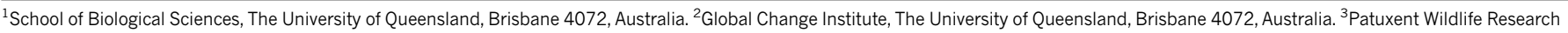

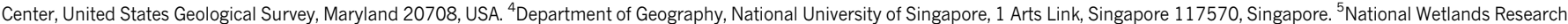

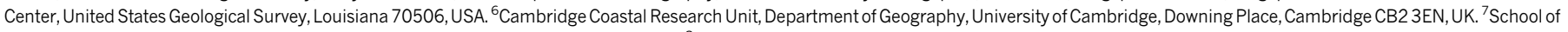

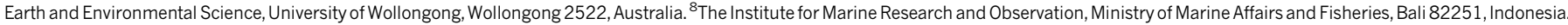

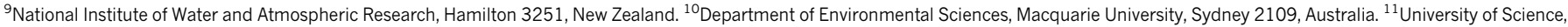
Vietnam National University, Ho Chi Minh City, Vietnam. ${ }^{12}$ International Crane Foundation, Wisconsin 53913, USA.
} 

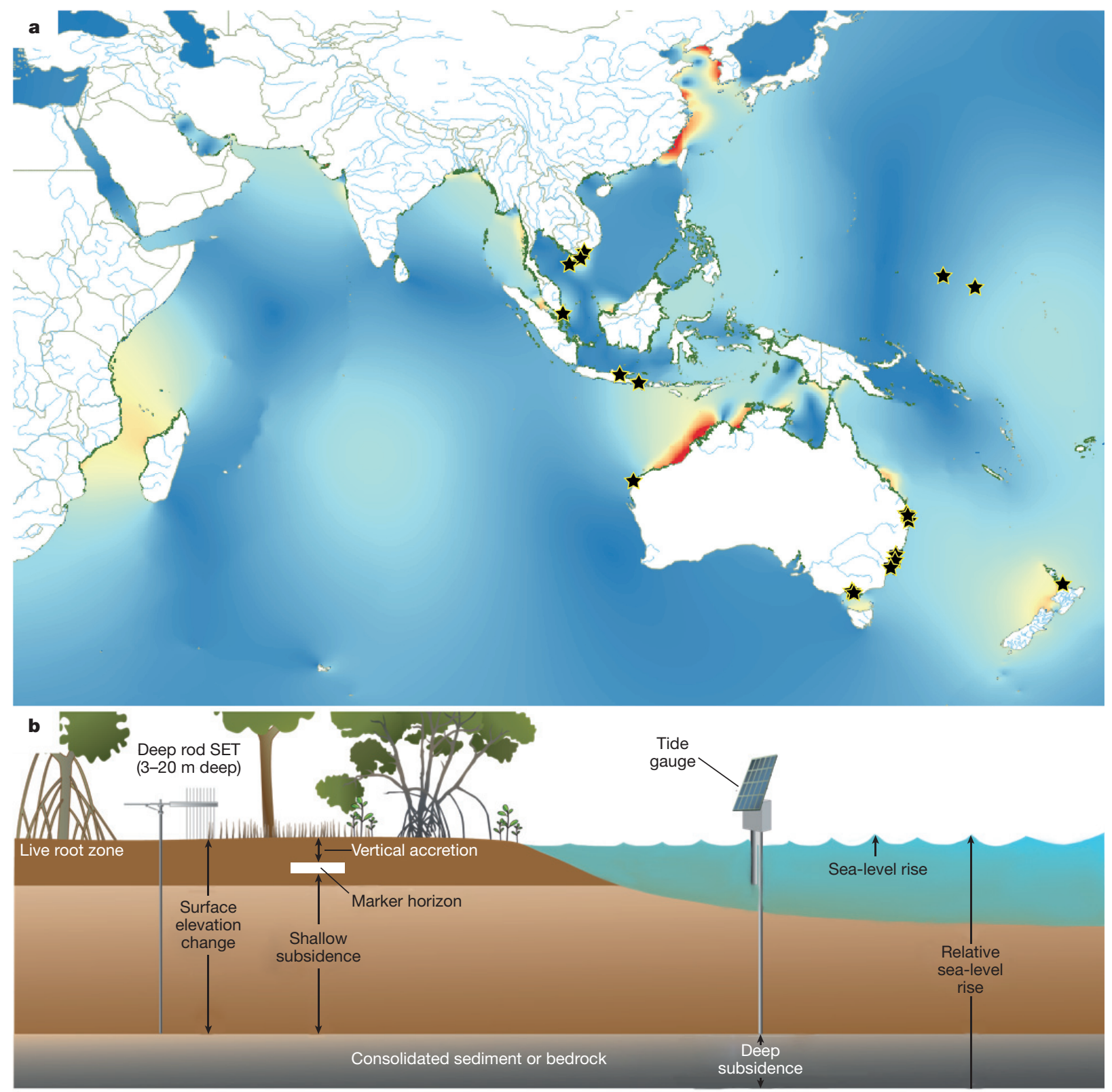

Figure $1 \mid$ Map of the Indo-Pacific region study sites and a schematic of the SET-MH. a, Study sites are indicated by stars; mangrove forests are shown in dark green. The colour of the coastal ocean represents variation in tidal range (Aviso + FES2012 tide model), where blue is microtidal $(0-2 \mathrm{~m})$, yellow is

the region is unlikely as a result of political uncertainty and because in many nations coastal inhabitants are 'trapped' by a lack of capital and available inland sites that would support migration ${ }^{21}$.

To examine the future vulnerability of Indo-Pacific mangroves to SLR, we developed a model of mangrove habitat suitability based on position in the tidal frame. Mangrove forests persist in the portion of the tidal frame from mean sea level (MSL) to the level of the highest astronomical tide, which generally corresponds to the highest elevation at which mangroves can survive $e^{22}$. This gives rise to what is termed a wetland's 'elevation capital', or the potential of an intertidal wetland to remain within a suitable inundation regime at that site (that is, above MSL) despite subsiding relative to local SLR ${ }^{23}$. For example, mangrove forests occupying high intertidal sites that have a 10-m tidal range (such as the Kimberly coast of Australia) would need to lose up to $5 \mathrm{~m}$ of elevation capital to reach MSL. In contrast, high intertidal sites with a tidal range of $1 \mathrm{~m}$ (such as the Caribbean and parts of Indonesia) mesotidal $(2-4 \mathrm{~m})$ and red is macrotidal $(>4 \mathrm{~m})$. b. The SET-MH installation monitors changes in soil-surface elevation, surface accretion above a marker horizon and shallow subsidence (by difference ${ }^{8,9}$ ); see Methods for details. would have to lose only $0.5 \mathrm{~m}$ of elevation to put the entire contemporary forest at or below MSL. Assuming that mangrove forest species cannot persist below approximately MSL, we estimate the time to inundation and thus loss of the forest by using tidal range as a surrogate for the elevation capital within the ecosystem.

Over the range of elevation deficits within our data set, we estimated the time until complete submergence of the forest at sites with varying tidal range (and thus varying elevation capital). This model, which subtracts elevation from the elevation capital over time, assumes constant rates of SLR. Assuming an elevation deficit of $20 \mathrm{~mm} \mathrm{yr}^{-1}$ (that is, sea level rising $20 \mathrm{~mm} \mathrm{yr}^{-1}$ faster than mangrove surface elevation gain), which occurs at some of our sites owing to high local rates of SLR and shallow subsidence (for example, Indonesia), we project complete submergence of the forests in 100 years wherever tidal ranges are less than $4 \mathrm{~m}$ (Extended Data Fig. 2). At an elevation deficit of $6 \mathrm{~mm} \mathrm{yr}^{-1}$ (the mean elevation deficit for our sites with elevation deficits), we 

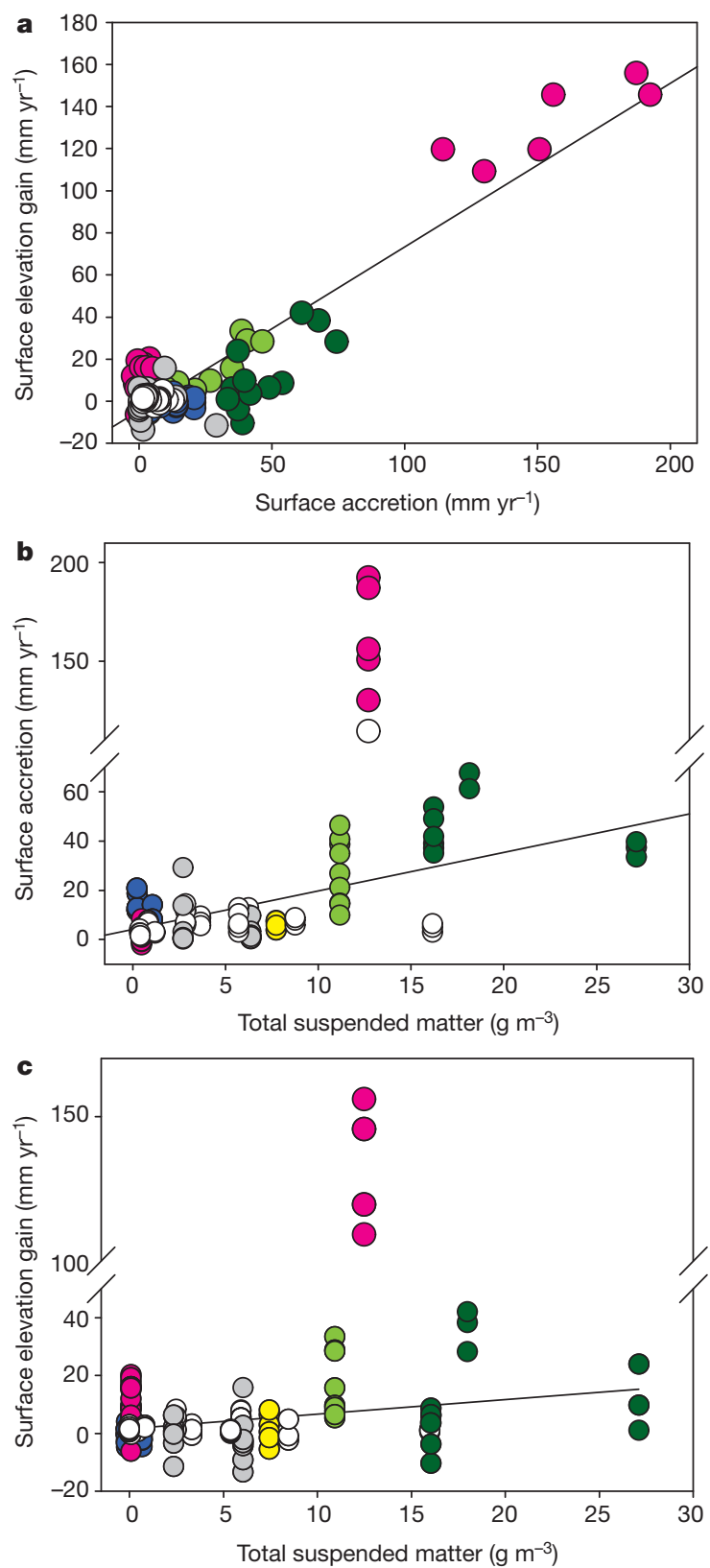

Figure $2 \mid$ The relationship between mangrove soil-surface elevation gains and sediment availability. a-c, Relationships between soil-surface elevation gains and accretion on the soil surface (a), accretion on the soil surface and average annual TSM derived from MERIS satellite imagery (b), and surface elevation gains and average annual TSM (c). Data points are coloured as follows: pink, Indonesia; dark green, Vietnam; light green, New Zealand; yellow, western Australia; dark blue, Micronesia; grey, Singapore; white, eastern Australia. Solid lines are linear regressions: a, (surface elevation gain $)=(-4.44 \pm 0.95)+(0.78 \pm 0.03) \times($ surface accretion $), R^{2}=0.849$, $P<0.0001, F$ test (for overall significance of the linear regression); $\mathbf{b}$, (surface accretion $)=(4.15 \pm 1.08)+(1.57 \pm 0.15) \times \mathrm{TSM}, R^{2}=0.443, P<0.0001$, $F$ test (excluding data from Porong, Indonesia); $\mathbf{c}$, (surface elevation gain $)=(1.38 \pm 0.83)+(0.51 \pm 0.11) \times \mathrm{TSM}, R^{2}=0.122, P<0.0001, F$ test (excluding data from Porong, Indonesia); the indicated uncertainties are standard errors. Source Data for this figure are available online.

estimate it would take 100-300 years for high intertidal forests to be lower than MSL, while at low elevation deficits $\left(1 \mathrm{~mm} \mathrm{yr}^{-1}\right)$ the forests may persist for thousands of years. The palaeorecord is consistent with high levels of persistence of mangroves through time when rates of SLR are low to moderate (that is, low levels of elevation deficits). For example, in Belize there is evidence that mangrove forests persisted

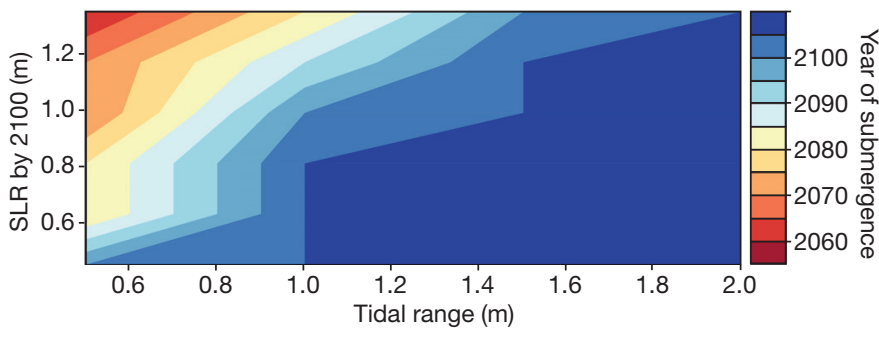

Figure 3 Year in which mangroves are predicted to be submerged at sites with low $\left(<2.5 \mathrm{~g} \mathrm{~m}^{-3}\right)$ sediment availability over variation in tidal range and rates of SLR. The darkest blue region indicates no submergence predicted within the modelling time frame (until 2100). At high sediment supply $\left(>2.5 \mathrm{~g} \mathrm{~m}^{-3}\right)$, mangrove forests were not predicted to be submerged by 2100 . See Methods for further details.

for long intervals over the Holocene epoch during periods when rates of SLR were less than $5 \mathrm{~mm} \mathrm{yr}^{-1}$ (ref. 15). Additionally, there is evidence that high intertidal mangrove forests in northern Australia persisted for thousands of years despite relatively high rates of SLR ${ }^{14}$. However, evidence of overwhelming flooding and loss of mangrove forests is also evident during past rapid rises in sea level ${ }^{14}$.

To synthesize the effects of sediment supply and accelerating rates of SLR (and corresponding elevation deficits) on the fate of mangrove forests, we formulated a second model that assessed the probable time to submergence of mangrove forests over the range of observed rates of surface elevation gains with no landward migration and over a range of tidal amplitudes. According to the model, mangrove forests are likely to persist at sites with high tidal range even with high rates of SLR and low levels of sediment availability (Fig. 3), consistent with palaeoobservations $^{14}$ and theory ${ }^{16,18}$. However, at sites with low tidal range, forests will be vulnerable by 2080 at moderate SLR $(0.8 \mathrm{~m}$ by 2100$)$.

We cannot estimate the absolute extent of losses of mangrove cover over the region because measurements of mangrove forest elevation in the region are too coarse; however, our model provides a semi-empirical indication of the conditions under which mangrove loss is likely with SLR and locations where management of sediment supply and space for landward migration are vital to ensure mangrove forests survive into the future. Our model indicates that the outlook for mangrove forests in some locations is poor under relatively low rates of SLR - the Intergovernmental Panel on Climate Change (IPCC) Representative Concentration Pathway 6 (RCP6) scenario-with submergence of mangroves by 2070 predicted in the Gulf of Thailand, the southeast coast of Sumatra, the north coasts of Java and Papua New Guinea and the Solomon Islands (Fig. 4). In contrast, the outlook for the persistence of mangroves into the future is more positive in east Africa, the Bay of Bengal, eastern Borneo and northwestern Australia, where there are relatively large tidal ranges and/or higher sediment supply.

Our model does not account for long-term and nonlinear feedbacks within the system where elevation deficits may be enhanced or reduced, for example, through episodic high-wave-energy events that cause ero$\operatorname{sion}^{24}$, degradation of forests ${ }^{25}$, other stochastic events such as intense storms that may alter hydrology or deliver sediment pulses ${ }^{26}$, or changes in ocean circulation that may influence regional rates of $\mathrm{SLR}^{7}$. The frequency and intensity of these events are predicted to increase under climate-change scenarios ${ }^{2}$, and all of these factors will influence the length of time before forest submergence and loss. Our model also does not include subsidence (or uplift) that occurs below the SET benchmark ${ }^{9}$, which in some locations may strongly influence the time until submergence. But shifts in the way sediment is managed, and reversing forest degradation and thus enhancing organic matter inputs to sediments may extend the persistence of mangroves for hundreds of years (for example, reducing elevation deficits by $6 \mathrm{~mm} \mathrm{yr}^{-1}$ extended the time until submergence from 83 years to 167 years for sites with a $2-m$ tidal range). In coastal and estuarine systems with reduced upstream sediment inputs due to human modifications ${ }^{27}$, the potential 

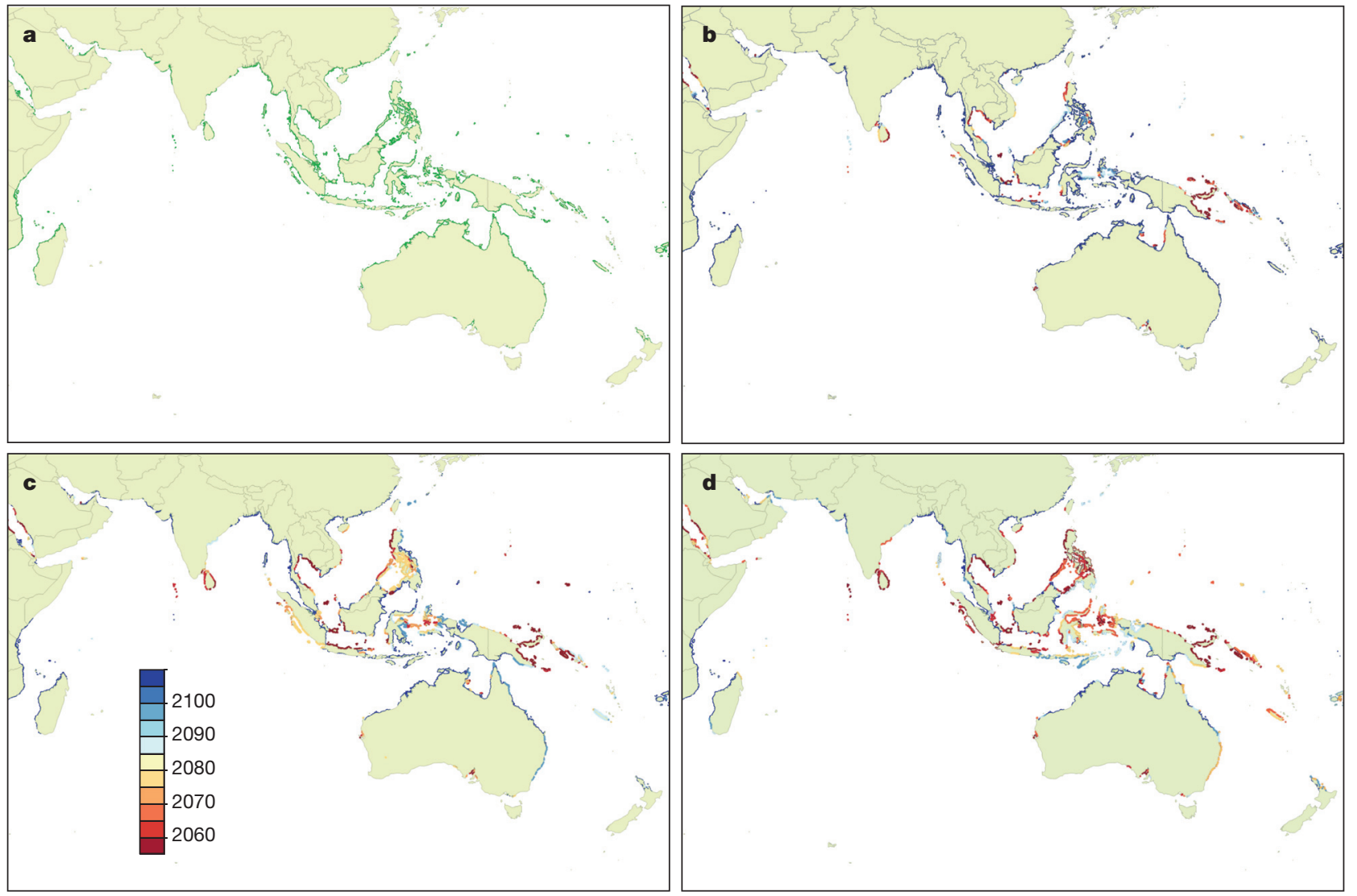

Figure 4 $\mid$ Mangrove forest distribution in the Indo-Pacific region. a, Dark green areas indicate current mangrove forests. $\mathbf{b}-\mathbf{d}$, Predicted decade of mangrove forest submergence, indicated by the colour scale in $\mathbf{c}$, for IPCC RCP6 (0.48 m SLR by 2100) (b), RCP8.5 (0.63 m SLR by 2100) (c), and a more

for eco-geomorphic feedbacks that delay the onset of mangrove-forest loss is diminished.

Data from our network of sites indicate that the fate of mangroves in the Indo-Pacific with SLR is strongly linked to the availability of suspended matter, which is important for increases in soil-surface elevation and enables mangroves to maintain their elevation within the tidal frame above MSL. The importance of sediment supply for the resilience of mangrove forests in the face of SLR has been inferred from the palaeontological record ${ }^{14}$ and from recent observed changes in mangrove coasts where sediment supply has been reduced, owing to damming of rivers ${ }^{27}$. In Thailand, there has been an $80 \%$ reduction of sediment supply in the Chao Phraya River delta, which, in combination with surface subsidence caused by groundwater extraction, has resulted in kilometres of mangrove shoreline retreat ${ }^{28}$. Within the Mekong River system, planned construction of dams and reductions in sediment supply ${ }^{28}$ will have a devastating effect on the local coastal sediment budget and the long-term persistence of mangrove forests. Management of the coast and particularly of the river systems that deliver much of the sediment to the region is therefore vital for the survival of mangrove forests. Although sediment supply at some sites may be maintained as a legacy of prior forest clearing of catchments (which leads to erosion of soil), the restriction of sediment supply caused by the building of dams is a major issue that will contribute to mangrove losses in the future.

More than half the mangrove forests we studied have already lost elevation relative to sea level. With constant rates of SLR where tidal ranges are large and sediment supplies are maintained, mangrove forests in the upper intertidal zone may survive thousands of years before they are threatened by submergence. However, under moderate extreme scenario (1.4 $\mathrm{m}$ SLR by 2100) (d). The darkest blue region indicates no submergence predicted within the modelling time frame (until 2100). The model assumes landward migration of mangrove forests is not possible.

emissions scenarios (for example, IPCC RCP6) at sites with low tidal ranges and low sediment supply, mangrove forests may be lost by 2080 . Our work emphasizes the urgent need to plan for the maintenance of sediment supply in river systems that are expected to be heavily modified and dammed in the future, to reverse forest degradation that reduces organic matter inputs and to plan for the landward migration of mangrove forests to higher elevations in locations where sediment supply is expected to be restricted.

Online Content Methods, along with any additional Extended Data display items and Source Data, are available in the online version of the paper; references unique to these sections appear only in the online paper.

Received 28 January; accepted 26 August 2015.

Published online 14 October 2015.

1. Nicholls, R. J. \& Cazenave, A. Sea-level rise and its impact on coastal zones. Science 328, 1517-1520 (2010).

2. Woodruff, J. D., Irish, J. L. \& Camargo, S. J. Coastal flooding by tropical cyclones and sea-level rise. Nature 504, 44-52 (2013).

3. Kirwan, M. L. \& Megonigal, J. P. Tidal wetland stability in the face of human impacts and sea-level rise. Nature 504, 53-60 (2013).

4. Giri, C. et al. Status and distribution of mangrove forests of the world using earth observation satellite data. Global Ecol. Biogeogr. 20, 154-159 (2011).

5. Milliman, J. D. \& Farnsworth, K. L. River Discharge to the Coastal Ocean: A Global Synthesis (Cambridge Univ. Press, 2011).

6. Church, J. A. et al. in Climate Change 2013: The Physical Science Basis. Working Group I Contribution to the Fifth Assessment Report of the Intergovernmental Panel on Climate Change (eds Stocker, T. F. et al.) Ch. 13 (Cambridge Univ. Press, 2013).

7. Stammer, D. et al. Causes for contemporary regional sea level changes. Annu. Rev. Mar. Sci. 5, 21-46 (2013).

8. Cahoon, D. R. etal. High-precision measurements of wetland sediment elevation: I. Recent improvements to the sedimentation-erosion table. J. Sediment. Res. 72, 730-733 (2002). 
9. Callaway, J. C., Cahoon, D. R. \& Lynch, J. C. in Methods in Biogeochemistry of Wetlands (eds DeLaune, R. D. et al.) 901-917 (Soil Science Society of America, 2013).

10. Webb, E. L. et al. A global standard for monitoring coastal wetland vulnerability to accelerated sea-level rise. Nature Clim. Change 3, 458-465 (2013).

11. Costanza, R. etal. Changes in the global value of ecosystem services. Global Environ. Change 26, 152-158 (2014).

12. Brander, L. M. et al. Ecosystem service values for mangroves in Southeast Asia: a meta-analysis and value transfer application. Ecosyst. Services 1, 62-69 (2012).

13. Ball, M. C. Ecophysiology of mangroves. Trees Struct. Funct. 2, 129-142 (1988).

14. Woodroffe, C. D. Response of tide-dominated mangrove shorelines in Northern Australia to anticipated sea-level rise. Earth Surf. Proc.. Land. 20, 65-85 (1995).

15. McKee, K. L., Cahoon, D. R. \& Feller, I. C. Caribbean mangroves adjust to rising sea level through biotic controls on change in soil elevation. Global Ecol. Biogeogr. 16, 545-556 (2007).

16. Kirwan, M. L. \& Murray, A. B. A coupled geomorphic and ecological model of tidal marsh evolution. Proc. Natl Acad. Sci. USA 104, 6118-6122 (2007).

17. Jennerjahn, T. C. et al. Environmental impact of mud volcano inputs on the anthropogenically altered Porong River and Madura Strait coastal waters, Java, Indonesia. Estuar. Coast. Shelf Sci. 130, 152-160 (2013).

18. Fagherazzi, S. et al. Numerical models of salt marsh evolution: ecological, geomorphic, and climatic factors. Rev. Geophys. 50, RG1002 (2012).

19. Krauss, K. W. etal. How mangrove forests adjust to rising sea level. New Phytol. 202, 19-34 (2014).

20. Saintilan, N. et al. Mangrove expansion and salt marsh decline at mangrove poleward limits. Global Change Biol. 20, 147-157 (2014).

21. Black, R., Bennett, S. R. G., Thomas, S. M. \& Beddington, J. R. Climate change: migration as adaptation. Nature 478, 447-449 (2011).

22. Alongi, D. M. Present state and future of the world's mangrove forests. Environ. Conserv. 29, 331-349 (2002).
23. Cahoon, D. R. \& Guntenspergen, G. R. Climate change, sea-level rise, and coastal wetlands. Nat. Wetl. Newslett. 32, 8-12 (2010).

24. Winterwerp, J. C. et al. Defining eco-morphodynamic requirements for rehabilitating eroding mangrove-mud coasts. Wetlands 33, 515-526 (2013).

25. Lang'at, J. K. S. et al. Rapid losses of surface elevation following tree girdling and cutting in tropical mangroves. PLoS ONE 9, e107868 (2014).

26. Cahoon, D. R. A review of major storm impacts on coastal wetland elevations. Estuar. Coast. 29, 889-898 (2006).

27. Giosan, L., Syvitski, J., Constantinescu, S. \& Day, J. Climate change: protect the world's deltas. Nature 516, 31-33 (2014).

28. Kondolf, G. M., Rubin, Z. K. \& Minear, J. T. Dams on the Mekong: cumulative sediment starvation. Water Resour. Res. 50, 5158-5169 (2014).

Supplementary Information is available in the online version of the paper.

Acknowledgements The Global Change Institute at The University of Queensland supported this collaboration, as did the Australian Research Council SuperScience grant number FS100100024 to the Australia Sea Level Rise Partnerships. D.R.C., G.R.G. and K.W.K. acknowledge support from the US Geological Survey Climate and Land Use Research and Development Program. Any use of trade, product, or firm names is for descriptive purposes only and does not imply endorsement by the US Government.

Author Contributions All authors participated in a collaborative workshop or contributed field data, contributed to the conceptualization of models and edited the manuscript.

Author Information Reprints and permissions information is available at www.nature.com/reprints. The authors declare no competing financial interests. Readers are welcome to comment on the online version of the paper. Correspondence and requests for materials should be addressed to C.E.L. (c.lovelock@uq.edu.au). 


\section{METHODS}

SET-MH method description. The SET and the later-developed rod-SET consist of a benchmark rod driven in sections through the soil profile to resistance, often to $10-25-\mathrm{m}$ depth in the soil or to when bedrock is reached (Fig. 1b). After installation of the benchmark rod, a portable horizontal arm is attached, and fixed points (usually four positions around the top of the rod) are used to measure the distance to the substrate surface using a series of vertical pins lowered to the soil surface (Fig. 1b). Total surface height measurements have confidence intervals of $\pm 1.3 \mathrm{~mm}$ (ref. 8). SET data are usually complemented with monitoring of accretion on the soil surface using artificial soil marker horizons typically made of feldspar, sand or other resistant material, which simultaneously allows users to quantify rates of vertical surface accretion (that is, sediment deposition; Fig. 1b). The complete SET-MH installation provides observations of net surface elevation change above the benchmark depth as well as accretion on the surface of the wetland. These values may be compared to infer whether surface or subsurface processes are contributing to surface elevation gains. For example, if accretion on the soil surface is equivalent to surface elevation gain, then accretion on the soil surface, whether of mineral or organic origin, is the major process contributing to elevation gain. However, if elevation gains are less than surface accretion, then shallow subsidence of the soil volume is inferred (Extended Data Fig. 1) Conversely, if elevation gains are greater than surface accretion, then expansion of the subsurface soil profile is inferred, which may be due to root growth ${ }^{8,9,15,23}$. Over many sites it has been repeatedly shown that vertical accretion on the soil surface is not a valid substitute for surface elevation change and that the complete set-up is necessary to identify the contribution of surface and shallow subsurface processes to surface elevation change at a specific site ${ }^{15,23,26}$. Repeated measurements allow description of net surface elevation change, which can be integrated with region-specific relative SLR (for example, tide-gauge data; see Supplementary Information) to determine whether the surface elevation of mangroves has kept pace with SLR over that time period.

Analysis of variation in surface elevation. Linear regression was used to describe the relationships between: (1) surface elevation gains and accretion of sediment on the soil surface; (2) accretion on the surface and TSM; and (3) surface elevation gains and TSM. Forms of these relationships are given in the legend of Fig. 2.

The relative influence (in per cent) of predictor variables on surface elevation change (in millimetres per year) was analysed using boosted regression tree (BRT) model ${ }^{29}$ developed using data from 153 observations and 10 predictors, with a tree complexity of 5 and learning rate of 0.005 . We developed three models using three different measures of sea-level variation at each site (Supplementary Table 1): the long-term rate of SLR at tide gauges (model 1); the rates of sea-level change over the period of the surface elevation gain measurements at tide gauges (model 2); and the rates of sea-level change based on satellite altimetry (model 3). On the basis of cross-validation, the mean percentages (s.e.m.) of deviance explained by models $1-3$ are $44.8 \%( \pm 10.5 \%), 38.2 \%( \pm 9.3 \%)$ and $40.9 \%$ $( \pm 8.9 \%)$, respectively. BRT modelling was done with $R$ version 3.0 .2 using packages dismo and $\mathrm{gbm}$. The BRTs were built with a 10 -fold cross-validation optimization, with a Gaussian distribution for surface elevation change. Stochasticity (bag fraction) was set to 0.5 . The final models were fitted with 5,850 trees. Geomorphological setting followed the classifications of ref. 30: river delta, tidal, lagoon or carbonate island. Ecological habitat followed the classifications of ref. 31: fringe, scrub, hammock, basin, overwash or riverine. Dominant tree genera were Avicennia, Rhizophora, Sonneratia; mangrove forests were classified as mixed forests at sites where no single genera was dominant.

Estimating time to submergence. Years to submergence over variation in tidal range was estimated by summing annual elevation deficits (Extended Data Fig. 2). Elevation deficit is the difference between the rate of local SLR and the rates of surface elevation gain. Where elevation deficits in our data were observed $(N=103)$, mean elevation deficit over our sites was $6 \mathrm{~mm} \mathrm{yr}^{-1}$ (dashed line in Extended Data Fig. 2). Extended Data Fig. 2 shows the years to submergence (on a logarithmic scale) of the highest intertidal mangrove forest over variation in tidal range (microtidal, blue; mesotidal, yellow; macrotidal, red), for a range of elevation deficits (1-20 $\left.\mathrm{mm} \mathrm{yr}^{-1}\right)$; see Extended Data Fig. 2.

Model to predict the year of submergence of mangrove ecosystems. A model to predict the year of submergence of mangrove ecosystems subject to accelerating rates of SLR was developed for various physical environmental contexts. The model was based on the observed rates of mangrove surface elevation change as a function of rate of SLR, suspended sediment availability and tidal range. The model was run from 2010 to 2100 in 10-year time steps (see Extended Data Fig. 3 for a summary of the modelling process).

The vertical range of mangrove distribution was assumed to be the upper $50 \%$ of the tidal range ${ }^{22}$. For example, if the tidal range was $1 \mathrm{~m}$, the vertical distribution of mangroves was assumed to be $0.5 \mathrm{~m}$. Assuming that mangroves were at their upper vertical limit of their range at the start of the simulations, the time until net elevation loss was equivalent to $50 \%$ of the magnitude of tidal range (in metres) was calculated as the time to mangrove submergence. In each time step, elevation deficit was calculated as the magnitude of SLR minus the magnitude of surface elevation gain. Total elevation deficit over the 90 -year simulation was calculated by summing the accumulated elevation deficits.

Elevation gain (in millimetres per year) caused by sediment accumulation for particular SLR and suspended-sediment scenarios was calculated according to the observed surface elevation data. The slope and intercept of linear models relating elevation gain to rate of SLR are given in Extended Data Table 2. The relationship between surface elevation gain and rate of SLR (in millimetres per year) was established for two TSM classes: low $\left(<2.5 \mathrm{~g} \mathrm{~m}^{-3}\right)$ and high $\left(>2.5 \mathrm{~g} \mathrm{~m}^{-3}\right)$. Linear regression was used to establish the functional forms of the relationships between surface elevation gain and the rate of SLR.

Scenarios of tidal ranges from $0.5 \mathrm{~m}$ to $2.0 \mathrm{~m}$ in $0.5-\mathrm{m}$ increments were examined ( 4 total). Six SLR trajectories were simulated for a total of 24 simulations. The starting rate of SLR for each trajectory was $3 \mathrm{~mm} \mathrm{yr}^{-1}$, equivalent to the current rate of global average SLR. The rate of change of sea-level increase was varied by $0.5 \mathrm{~mm} \mathrm{yr}^{-1}$ in decadal time steps for the six trajectories: SLR increased by $0.5 \mathrm{~mm} \mathrm{yr}^{-1}$ each decade in the first trajectory, $1 \mathrm{~mm} \mathrm{yr}^{-1}$ in the second, $1.5 \mathrm{~mm} \mathrm{yr}^{-1}$ in the third and so on, up to $3.0 \mathrm{~mm} \mathrm{yr}^{-1}$ each decade in the last trajectory. The resultant magnitudes of sealevel change for the six trajectories were $0.45 \mathrm{~m}, 0.63 \mathrm{~m}, 0.81 \mathrm{~m}, 0.99 \mathrm{~m}, 1.17 \mathrm{~m}$ and $1.35 \mathrm{~m}$ by 2100 . The model was run for each of the tide-range $(N=4)$ and SLR $(N=6)$ trajectory combinations, for each of the sediment availability scenarios (low and high), for a total of 48 simulations.

We then created spatial layers of the model. The TSM layer was classified as high $\left(>2.5 \mathrm{~g} \mathrm{~m}^{-3}\right)$ or low $\left(<2.5 \mathrm{~g} \mathrm{~m}^{-3}\right)$. The tidal-range layer was sourced from the FES2012 tidal model package distributed by AVISO, with support from CNES (http://www.aviso.altimetry.fr/) ${ }^{32}$. We ran the model for each pixel that contains mangroves, as indicated by the data presented in ref. 4 , for three SLR scenarios (RCP6.5, RCP8.5 and a higher, 1.4-m SLR by 2100 scenario based on ref. 33).

There are a number of assumptions and limitations to this approach. First, we assumed that mangroves commenced the simulations at the upper vertical limit of their range. Therefore, mangroves at lower vertical extents would submerge earlier and the model is an optimistic estimate of time until submergence. Second, while feedbacks between surface elevation change and other environmental features (sediment supply, vertical location in the tidal frame and so on) were not explicitly incorporated, they were implicitly included as they would have contributed to the observed SET data upon which the model was built. Third, we assumed that mangroves would be submerged when they reached MSL ( $50 \%$ of the tidal range). However, mangroves may be able to persist beyond this time (that is, there may be a time lag), owing to physiological tolerance and acclimatization. If this time lag were to exist, then it would extend the time frame for which mangroves would be expected to survive after submergence. Lastly, the model does not consider the area of habitat, or predict when new habitat would become available.

Time scales of soil surface elevation records. The timescale of SET measurements is relatively short compared to the timescales of ecosystem change in response to SLR; therefore, to assess whether SET measurements are representative of longer term rates of surface elevation change we took two approaches. The first uses SET records of differing lengths to compare shorter- and longer-term rates. The second compares SET elevation gains with those inferred from ${ }^{210} \mathrm{~Pb}$ dating of sediment cores (over the scale of decades) for the few sites where sediment dating and SET data are available.

To assess whether the length of the SET record is likely to influence our results, surface elevation gains measured over longer periods (mean record length of 5.5 years) were compared to those over shorter periods (mean record length of 2.1 years) for three sites (New Zealand, $N=3$; Micronesia, $N=13$; Moreton Bay, Australia, $N=18)$. Longer-term and shorter-term rates were highly correlated $\left(R^{2}=0.59\right)$ with a slope of $0.90 \pm 0.13$ which was not statistically different from 1 ( $t=0.769, P=0.45$ ) (Extended Data Fig. 4). The lengths of the SET records were not correlated with surface elevation gain, surface accretion, shallow subsidence or elevation deficits relative to SLR. Six SETs in Micronesia have now been monitored for 16.6 years. At this site, surface elevation gains at 16.6 years were correlated with surface elevation gains at 6.6 years: (surface elevation at $16.6 \mathrm{yr})=-0.16+(0.36 \pm$ $0.12) \times($ surface elevation at $6.6 \mathrm{yr}), R^{2}=0.59$. Thus, in Micronesia, the long-term elevation gain was approximately $40 \%$ of the short-term rate, indicating compaction of the sediment profile over time. ${ }^{210} \mathrm{~Pb}$ dating of sediment cores and SET data are available for the New Zealand site and also for locations on the east coast of Australia. In New Zealand, sediment accumulation rates measured using SETs and those using ${ }^{210} \mathrm{~Pb}$ (from the 1960 s to the present) are similar ${ }^{34}$. In Moreton Bay, the mean rate of mangrove sediment accumulation using ${ }^{210} \mathrm{~Pb}$ was $1.2 \pm 0.9 \mathrm{~mm} \mathrm{yr}^{-1}$, which is lower, but in the range of that observed using SETs in similar habitats $\left(1.7 \pm 0.5 \mathrm{~mm} \mathrm{yr}^{-1}\right.$; ref. 35$)$; in southeastern Australia, ${ }^{210} \mathrm{~Pb}$ was $1.7 \pm 0.3 \mathrm{~mm} \mathrm{yr}^{-1}$, which is higher than that observed using SETs $(0.72 \pm 0.49 \mathrm{~mm}$ 
$\mathrm{yr}^{-1}$; ref. 35). Additionally, rates of surface elevation gain measured with SETs in the Caribbean and Florida are broadly consistent with sediment accumulation rates derived from ${ }^{14} \mathrm{C}$ dating ${ }^{15}$ and ${ }^{210} \mathrm{~Pb}$ dating ${ }^{36}$. The study in Florida ${ }^{36}$ found sediment accumulation based on ${ }^{210} \mathrm{~Pb}$ was on average $81 \%$ of that measured using 2.5 -yr SET records. Compaction can be caused by loss of pore space due to dewatering and grain packing, and compression and decomposition of organic matter, which may not occur linearly over time $e^{37}$. Variation in sediment characteristics are likely to lead to variable rates of compaction over the Indo-Pacific region. If high rates of compaction are typical, then our short-term rates may over-estimate surface elevation gains for the region.

Total suspended matter in coastal waters. In this study we used level-3-processed TSM data at $4-\mathrm{km}$ resolution and binned monthly (data freely available from http://hermes.acri.fr/). TSM concentration was derived from the MERIS instrument on the European Space Agency's (ESA) Envisat satellite (390$1,040 \mathrm{~nm})$. TSM in coastal waters is an indicator of suspended sediments associated with river run-off and resuspension and is useful in both estuarine and reef lagoon waters ${ }^{38}$. Data products were processed and validated as part of the ESA's DUE GlobColour Global Ocean Colour for Carbon Cycle Research project (for more information on data processing see http://www.globcolour.info/CDR_Docs/ GlobCOLOUR_PUG.pdf). The resulting raster grid was displayed in the platecarrée projection. TSM was extracted using the open-source software BEAM VISAT (http://www.brockmann-consult.de/cms/web/beam/; ESA), using the TSM value of the pixel containing, or closest to, the SET site. For 24 sites, we used data from the pixel containing the SET site (that is, within $4 \mathrm{~km}$ of the site); 3 sites were 1 pixel distant and 3 sites were greater than 1 pixel distant ( 2 pixels for Kooragang Island, 5 pixels for Quail and 17 pixels for Porong). The Porong region has limited data availability owing to high cloud cover. An annual mean for 2011, where data from all sites was available, was calculated by averaging TSM pixel data for January, April, July and October. In other years, TSM from many sites were missing from the data set. We used mean annual data in 2011 to assess relation- ships between sediment accretion and TSM. Comparison of TSM values over the different years the data were available (since 2002) found that spatial differences were consistent over years. The relationship between mean TSM in 2011 and mean over the available record is shown in Extended Data Fig. 5. The linear regression of this relationship is (mean TSM in 2011) $=(1.38 \pm 0.94)+(0.58 \pm 0.08) \times($ mean TSM over all available years), $R^{2}=0.64, P<0.0001, F$ test, where the indicated uncertainties are standard errors.

29. Elith, J., Leathwick, J. R. \& Hastie, T. A working guide to boosted regression trees. J. Anim. Ecol. 77, 802-813 (2008).

30. Woodroffe, C. in Tropical Mangrove Ecosystems (eds Robertson, A. I. \& Alongi, D. M.) Ch. 2 (American Geophysical Union, 1993).

31. Lugo, A. I. \& Snedaker, S. C. The ecology of mangroves. Annu. Rev. Ecol. Syst. 5, 39-64 (1974).

32. Carrère, L., Lyard, F., Cancet, M., Guillot, A. \& Roblou, L. FES 2012: a new global tidal model taking advantage of nearly 20 years of altimetry. In Proc. 20 years of Progress in Radar Altimetry Symp. ESA SP-710 (2012).

33. Horton, B. P., Rahmstorf, S., Engelhart, S. E. \& Kemp, A. C. Expert assessment of sealevel rise by AD 2100 and AD 2300. Quat. Sci. Rev. 84, 1-6 (2014).

34. Swales, A., Bentley, S. J. \& Lovelock, C. E. Mangrove-forest evolution in a sedimentrich estuarine system: opportunists or agents of geomorphic change? Earth Surf. Proc. Land. 40, 1672-1687 (2015).

35. Rogers, K. Saintilan, N. \& Heijnis, H. Mangrove encroachment of salt marsh in Western Port Bay, Victoria: the role of sedimentation, subsidence and sea level rise. Estuaries 28, 551-559 (2005).

36. Cahoon, D. R. \& Lynch, J. C. Vertical accretion and shallow subsidence in a mangrove forest of southwestern Florida, U.S.A. Mangroves Salt Marshes 1, 173-186 (1997).

37. Woodroffe, C. D. et al. Mangrove sedimentation and response to relative sea-leve rise. Annu. Rev. Mar. Sci. Preprint at http://www.annualreviews.org/doi/abs/ 10.1146/annurev-marine-122414-034025.

38. Blondeau-Patissier, D. et al. ESA-MERIS 10-year mission reveals contrasting phytoplankton bloom dynamics in two tropical regions of Northern Australia. Remote Sens. 6, 2963-2988 (2014). 


\section{RESEARCH LETTER}
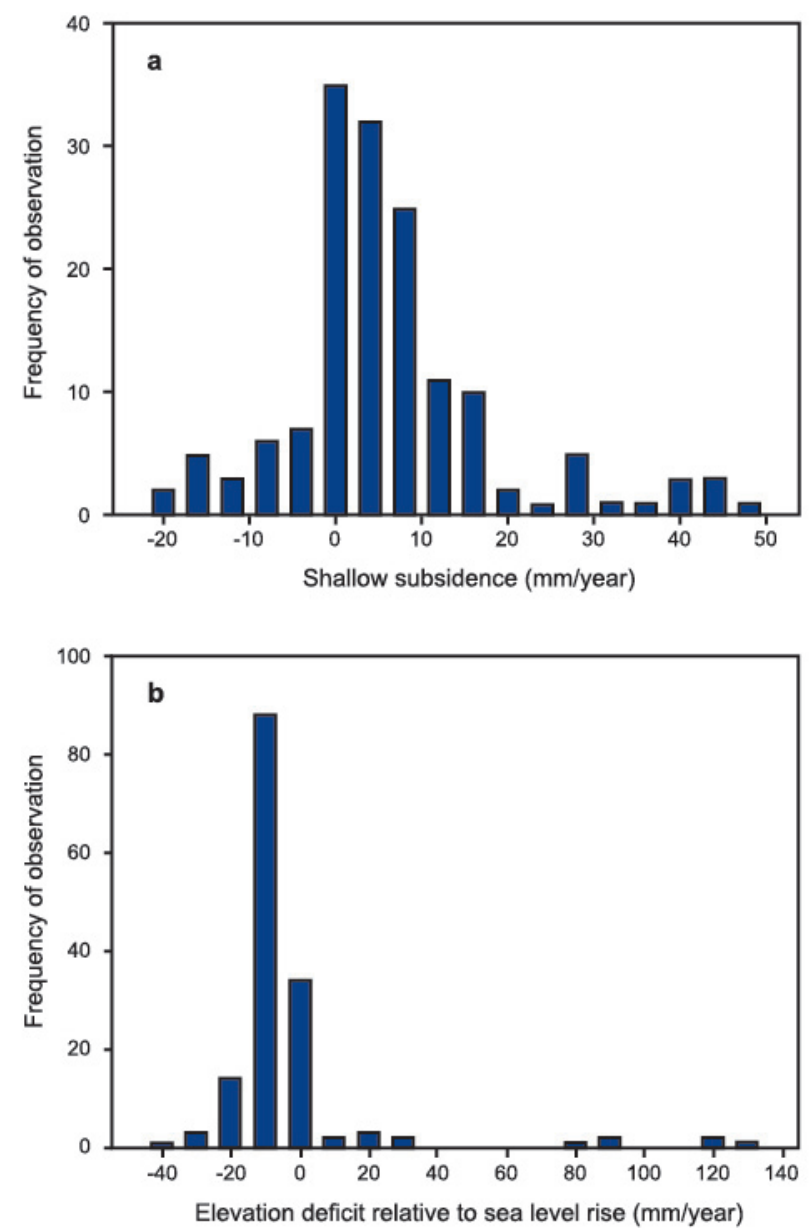

Extended Data Figure 1 Frequency distributions of values of shallow subsidence and elevation deficits. a, The frequency distribution of shallow subsidence over all the SET sites, calculated as (surface accretion) - (surface elevation gain). (The data presented here are available online from the Source Data of Fig. 2). b. The frequency distribution of surface elevation deficits relative to SLR from tide gauges (see Supplementary Table 1). 


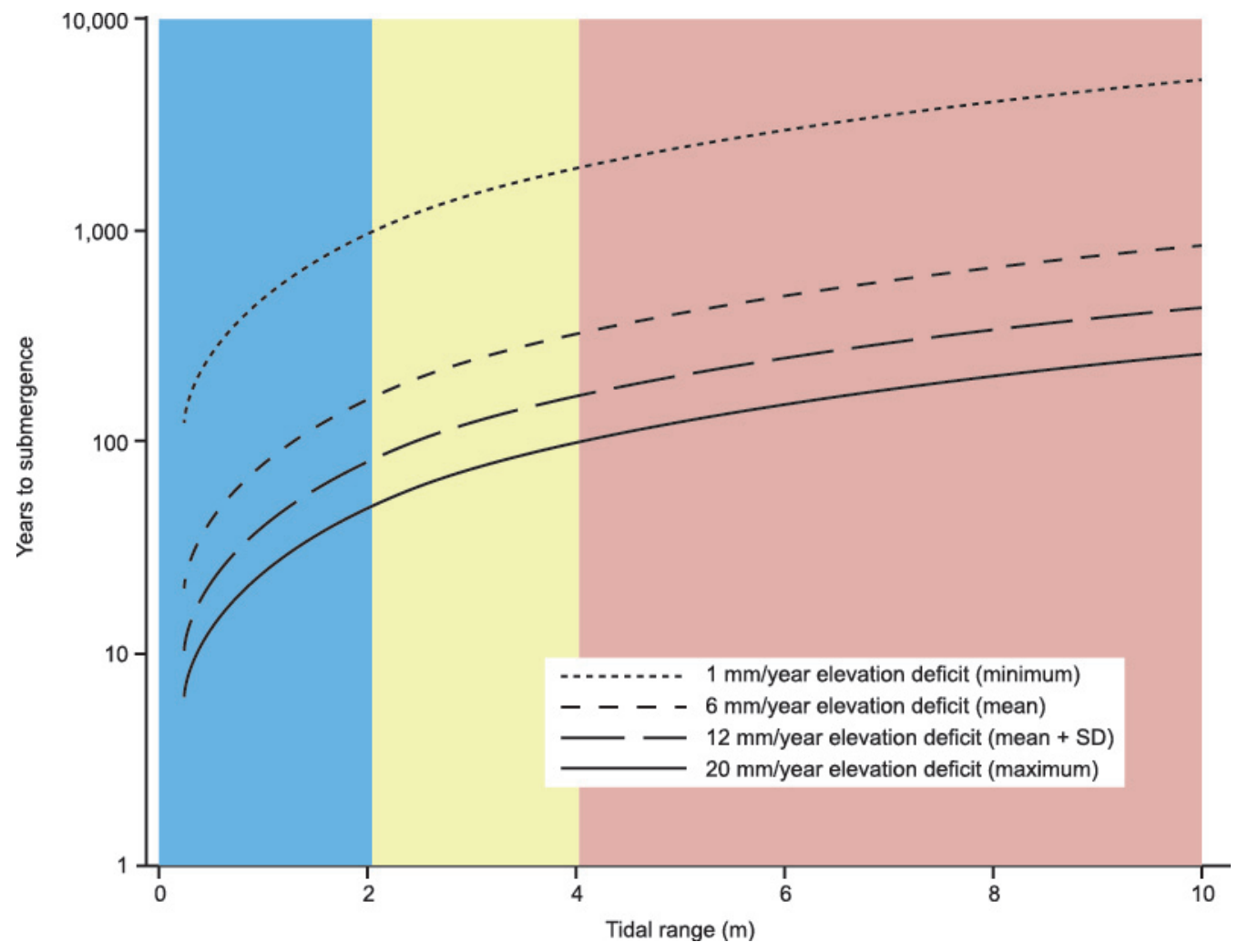

Extended Data Figure $2 \mid$ Years until submergence (logarithmic scale) of the highest intertidal mangrove forest over variation in tidal range and for a range of elevation deficits. The elevation deficit is the difference between the rate of local SLR and the rate of surface elevation gain. Submergence is assumed to occur when the cumulative elevation deficit is equivalent to the elevation capital (defined as half the tidal range). The mean elevation deficit in our study was $6 \mathrm{~mm} \mathrm{yr}^{-1}$ (dashed line); other elevation deficits shown are $12 \mathrm{~mm} \mathrm{yr}^{-1}$ $\left(\right.$ mean $+\mathrm{SD}=6+6.3$; long-dashed line), $1 \mathrm{~mm} \mathrm{yr}^{-1}$ (minimum; dotted line) and $20 \mathrm{~mm} \mathrm{yr}^{-1}$ (maximum; solid line). Categories of tidal range are coloured blue for microtidal, yellow for mesotidal and red for macrotidal. 


\section{RESEARCH LETTER}

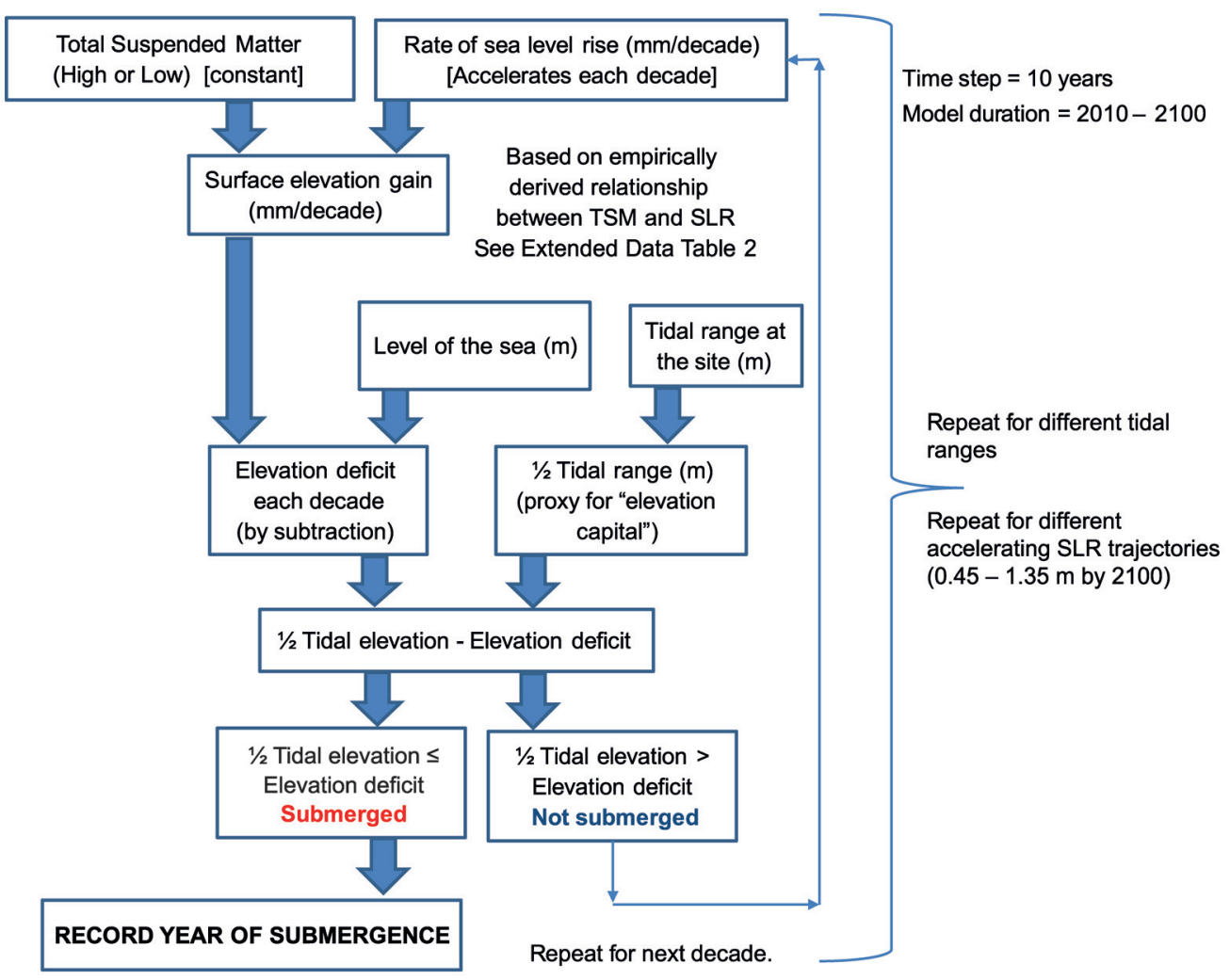

Extended Data Figure $3 \mid$ Schematic summary of the modelling process for estimating the decade of submergence of mangrove forests with SLR. 


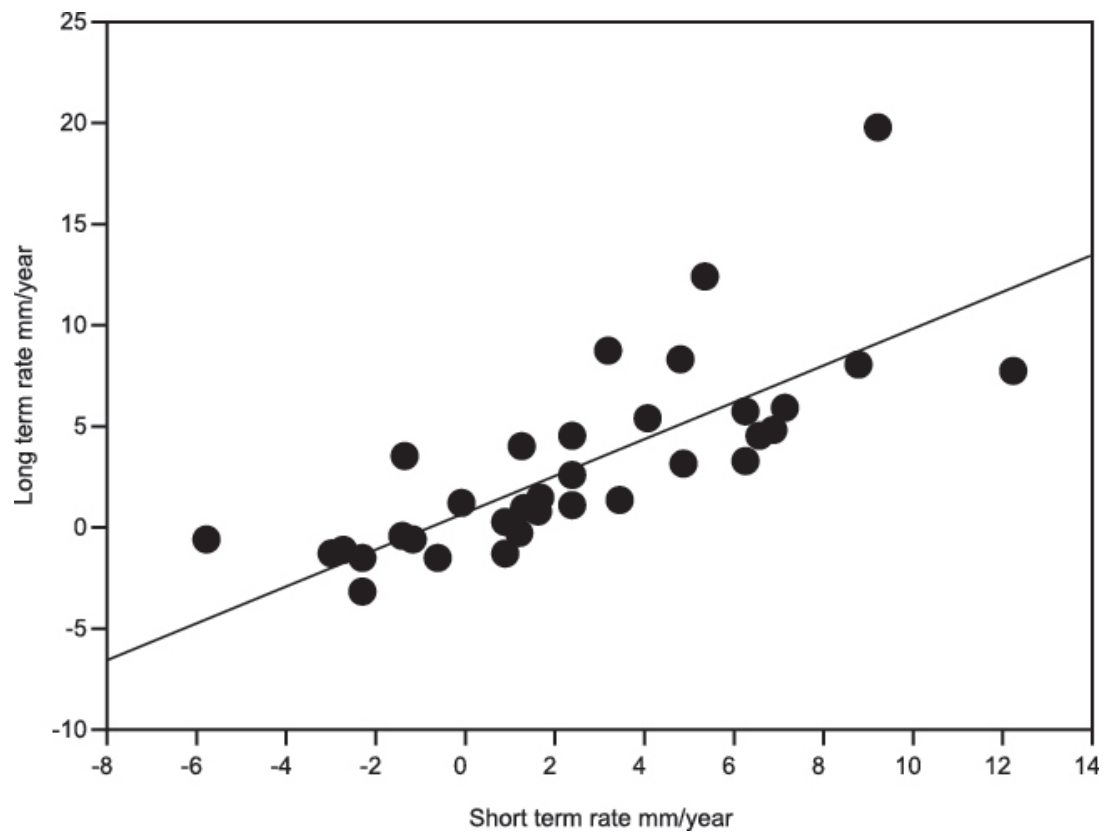

Extended Data Figure $4 \mid$ Comparison of surface elevation gains measured over longer and shorter periods for three sites. The three sites are New Zealand $(N=3)$, Micronesia $(N=13)$ and Moreton Bay, Australia $(N=18)$. The long-term mean record length is 5.5 years; the short-term mean record length is 2.1 years. Longer-term and shorter-term rates were highly correlated $\left(R^{2}=0.59\right)$ with a slope of $0.90 \pm 0.13$, which is not statistically different from 1 $(t=0.769, P=0.45)$. 


\section{RESEARCH LETTER}

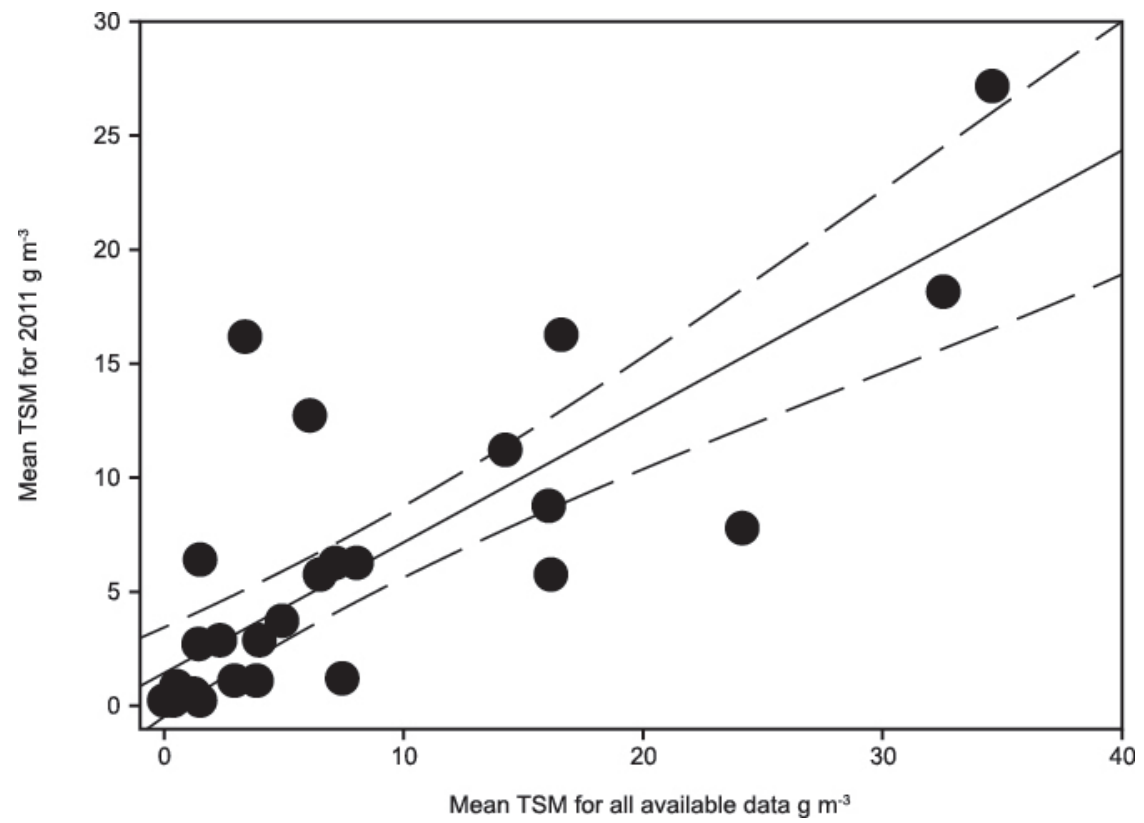

Extended Data Figure $5 \mid$ The relationship between mean TSM in 2011 over the available TSM record (2002-2011). In 2011, all sites were represented in $($ mean TSM in 2011$)=(1.38 \pm 0.94)+(0.58 \pm 0.08) \times($ mean TSM over all available years), $R^{2}=0.64, P<0.0001, F$ test, where the indicated uncertainties the MERIS data set. The linear regression (solid line) of this relationship is are standard errors. Dashed lines are $95 \%$ confidence intervals. 
Extended Data Table 1 | Summary of the relative influence of predictor variables on surface elevation change for BRT models

\begin{tabular}{|c|c|}
\hline Model predictor & Relative Influence (\%) \\
\hline \multicolumn{2}{|l|}{ Model 1} \\
\hline Total Suspended Matter (annual mean) $\mathrm{g} \mathrm{m}^{-3}$ & 36.47 \\
\hline Sea level change at tide gauge ( $\mathrm{mm} / \mathrm{year})$ & 29.32 \\
\hline Longitude & 8.81 \\
\hline Geomorphological setting & 7.19 \\
\hline Ecological habitat & 5.36 \\
\hline Latitude & 5.20 \\
\hline Dominant tree genera & 3.68 \\
\hline Annual rainfall $(\mathrm{mm})$ & 2.84 \\
\hline Tidal range $(\mathrm{m})$ & 1.12 \\
\hline \multicolumn{2}{|l|}{ Model 2} \\
\hline Total Suspended Matter (annual mean) $\mathrm{g} \mathrm{m}^{-3}$ & 37.40 \\
\hline Sea level change during the SET measurement ( $\mathrm{mm} /$ year) & 30.00 \\
\hline Longitude & 8.56 \\
\hline Geomorphological setting & 6.99 \\
\hline Ecological habitat & 5.82 \\
\hline Latitude & 4.00 \\
\hline Dominant tree genera & 4.08 \\
\hline Annual rainfall $(\mathrm{mm})$ & 2.12 \\
\hline Tidal range $(\mathrm{m})$ & 1.06 \\
\hline \multicolumn{2}{|l|}{ Model 3} \\
\hline Total Suspended Matter (annual mean) $\mathrm{g} \mathrm{m}^{-3}$ & 53.38 \\
\hline Sea level change from satellite altimetry ( $\mathrm{mm} /$ year) & 3.02 \\
\hline Longitude & 14.22 \\
\hline Geomorphological setting & 6.77 \\
\hline Ecological habitat & 5.08 \\
\hline Latitude & 4.97 \\
\hline Dominant tree genera & 5.72 \\
\hline Annual rainfall $(\mathrm{mm})$ & 3.17 \\
\hline Tidal range $(\mathrm{m})$ & 3.66 \\
\hline
\end{tabular}




\section{RESEARCH LETTER}

Extended Data Table 2 | Parameters used in the model for estimating time to submergence of mangrove forests for different sediment availability (classes of TSM).

\begin{tabular}{llllll}
\hline $\begin{array}{l}\text { Sediment availability } \\
\text { classes }\end{array}$ & Slope & $\begin{array}{l}\text { Standard error of } \\
\text { estimate }\end{array}$ & Intercept & \multicolumn{2}{c}{$\begin{array}{l}\text { Standard error } \\
\text { of estimate }\end{array}$} \\
\hline Low $\left(<2.5 \mathrm{~g} \mathrm{~m}^{-3}\right)$ & 0.36 & 0.04 & 0.29 & 0.53 & 0.45 \\
High $\left(>2.5 \mathrm{~g} \mathrm{~m}^{-3}\right)$ & 5.84 & 0.28 & -24.6 & 2.49 & 0.85 \\
\hline
\end{tabular}

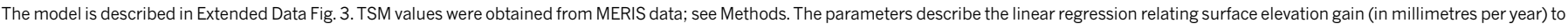
SLR (in millimetres per year) for two sediment availability bins, averaged over all tidal ranges; see Fig. 3. 